\title{
ANTIOXIDANT PROPERTIES OF SOME EXTRACTS FROM GAMMA IRRADIATED TOMATO (Lycopersicon esculentum L.) POMACE \\ Khalaf H. H. ${ }^{1}$;A.M.Sharoba ${ }^{1}$; R.A.El Sadani ${ }^{1}$;Fawzia M.EI Nashaby ${ }^{2}$
} and S. M. Elshiemy ${ }^{2}$

${ }^{1}$ : Food Science Department, Faculty of Agriculture, Benha University, Egypt.

2: Nuclear Research Center, Atomic Energy Authority, Cairo, Egypt,

${ }^{*}$ Corresponding author: Sabry Mohamed Elshiemy, plant Research Department, Nuclear Research Center, Atomic Energy Authority, Cairo, Egypt

Tel.: +2 01009201069; +20132763602

E-mail address: Dr.sabry_elshiemy@yahoo.com

\begin{abstract}
In this study, the gamma radiation processing of tomato pomace samples was carried out at dose levels of $0,1,3$ and $5 \mathrm{kGy}$. The total phenolic content, total flavonoids content and antioxidant activity properties of both non-irradiated and irradiated samples extracted in acetone $70 \%$, methanol and chloroform: ethyl acetate (1:1) were assessed. The obtained data showed that, the total phenolic content increased with an increase in radiation dose for all extractions. Extracted Phenolic content from tomato pomace by using acetone $(70 \%)$ was higher than those extracted by other solvents, whereas the phenolic content in acetone extract was increased from $182.579 \mathrm{mg} \mathrm{GAE} / 100 \mathrm{~g}^{-1}$ for the control sample to $191.445 \mathrm{mg} \mathrm{GAE} / 100 \mathrm{~g}^{-1}$ for the $3 \mathrm{kGy}$ radiation-processed samples. Three methods were carried out to determine the antioxidant activity of tomato pomace, the first method was the radical scavenging activity against 2, 2'-diphenyl-1-picrylhydrazyl (DPPH), acetone extract exhibited greater scavenging activity than those extracted by other solvents. The same trend was also observed by using the second method of $\beta$ - carotene bleaching assay and third method of ferric reducing antioxidant power (FRAP). The Highest ratio of $\beta$ carotene reducing power was achieved with acetone extract at $3 \mathrm{kGy}$ whereas reached to $61.14 \%$. Twelve phenolic acids component were identified in both nonirradiated and irradiated at 3kGy tomato pomace extracts by HPLC. Acetone extract of gamma irradiated and non-irradiated tomato pomace was tested for this antioxidant activity against oxidative stability of sunflower oil. The overall results indicated that, the highest oxidative stability $(10.6 \mathrm{hr}$.) was obtained by using gamma irradiated tomato pomace at $3 \mathrm{kGy}$ extract compared with those of the other doses. Finally, the obtained data showed that, tomato pomace is a very promising source of bioactive compounds and it is a very potential natural source of antioxidant compounds.

Keyword: Tomato pomace- gamma irradiation - phenolic compounds - Flavonoid compounds-Antioxidant activity -High performance liquid chromatography (HPLC).
\end{abstract}

\section{INTRODUCTION}

Tomato is one of the world's major vegetable with a worldwide and Egypt production of 161.8 and 8.6 million tons, respectively (FAOSTAT, 2012). It is an excellent source of many nutrients and secondary metabolities that are 
important for human health; minerals, vitamin $\mathrm{C}$ and $\mathrm{E}, \mathrm{B}$-carotene, lycopene, flavonoids, organic acids, phenolics and chlorophyll (Giovanelli and Paradise, 2002).

Tomatoes are widely consumed either raw or after processing and can provide a significant proportion of the total antioxidants in the diet (Martinez-Valvercle et al., 2002). Tomatoes constitute the predominant source of lycopene and phenols in the Egyptian diet because of their yearround availability, high utility in Egyptian culinary preparations and their cheap price. However, when tomatoes are processed into products like Catsup, tomato paste and sauces, $10-30 \%$ of their weight becomes waste or pomace (King and Zeidler, 2004). The pomace consists of the crushed skins and seeds of the fruit. It is rich in protein $(20-23 \%$ on dry basis) and fat $(12-18 \%$, mostly located in the seeds), while crude fibers comprise the third main component (12-30\%) (Liadakis, 1999). Food by-products usually represent an environmental problem for the industry, and many studies have been carried out about the potential utilization of several vegetable origin byproducts for their inclusion in the human diet, which could reduce industrial costs and justify new investments in equipment, providing a correct solution for the pollution problem connected with food processing (Lario et al., 2004).

Several other organic micronutrients, such as carotenoids and polyphenols, impart health benefits. Carotenoids are mostly used as natural food colorants, but also some of them (B-carotene, apocarotenal) have a vitamin A activity as well as antioxidant activity in vitro and in vivo (Kiokias and Gordon 2004). Polyphenols also act as antioxidants; they scavenge free radicals which are responsible for serious diseases and for the oxidation of lipids, proteins, and DNA. Several studies have revealed their antimicrobial, antithrombotic, antimutagenic, and anticarcinogenic activities (Kandaswami and Middleton, 1997and Sahu and Green, 1997). In addition to health benefits, the supplementation of food products with antioxidants delays the formation of off-flavors and rancidity and extends the shelf life of the product. Carotenoids and polyphenols are extensively distributed in several plant byproducts. Thus most fruit and vegetable by-products could serve as raw materials for their recovery. Moreover, these antioxidants or colorants would have a natural origin, which is in accordance with the demands of consumers for "all natural" because of the possible toxicity of synthetic additives. AlWandawi et al. (1985) reported that tomato peel contains high levels of lycopene compared to the pulp and seeds. In addition, tomato skin and seeds were reported to contain essential amino acids and the tomato seeds had higher amounts of minerals ( $\mathrm{Fe}, \mathrm{Mn}, \mathrm{Zn}$ and $\mathrm{Cu}$ ). Stewart et al. (2000) reported that the majority of the flavonoids in tomatoes are present in the skin. Similarly, Sharma and Le Maguer (1996) observed that most of the lycopene was associated with the skin and water insoluble fraction of the tomato pulp. George et al. (2004) studied that antioxidant compounds in 12 field grown tomato genotypes and reported that on average, the tomato skin had 2.5 times higher lycopene levels than the pulp. The skin of fruits and vegetables is commonly removed because they are thought to be indigestible and contain low levels of nutrients, furthermore, approximately one third of 
total weight of tomatoes in the form of skin and seeds are discarded during processing of tomatoes into paste (Al-Wandawi et al., 1985).

The antioxidants are isolated by solvent extraction and both extraction yield and antioxidant activity of the extracts are strongly dependent on the solvent, due to the variant antioxidant potential of compounds with different polarity. Nonpolar solvents (hexane and petroleum ether) can be used for the recovery of tocopherols and certain phenolic terpenes. Ethyl ether and ethyl acetate are very efficient for the recovery of flavonoid aglycons, low-molecular-weight phenols, and phenolic acids. Solvents of higher polarity (ethanol or ethanol-water mixtures) additionally can extract flavonoid glycosides and higher molecular weight phenols, resulting higher yields of total extracted polyphenols. However, that can range in size from monomers to long-chain polymers such as tannins, and usually exist bound to carbohydrates or as part of repeating subunits of high molecular weight polymers. Acetone results were the highest yield compared to ethanol, petroleum ether, and hexane (Aravantinos-Zafiris et al., 1992).

On the other hand gamma irradiation is approved by the Food and Drug Administration and the United States Department of Agriculture to preserve various food products. The U.S. Food and Drug Administration (1981) concluded that food irradiated at 50 kGy or less can be considered safe for human consumption. Various forms of Irradiation have been shown to influence the phenolic content of foods and their by-products. Far-infrared has also been used to release low-molecular- weight phenolics with antioxidant activity from food by-products for instance rice hulls and sesame meal extracts (Lee et al., 2003 and 2005). Gamma irradiation (10 kGy) increased phenolic acid content in cinnamon and clove, while phenolic content in nutmeg remained unaltered (Variyar et al., 1998 and Cantos et al., 2000). Additionally, new trials for increasing biological activities of natural product by gamma irradiation showed advantage in increasing yields, improved the color and antioxidant activity (Byun et al., 1999; Jo et al., 2003 and Kim et al., 2006). There is a growing scientific interest in the influence of irradiation processes on antioxidant activity and the compounds responsible for such activity. Several studies on plant materials showed that gamma irradiation does maintain or enhance antioxidant properties (Byun et al., 2002). However, some studies have shown that gamma irradiation decreased the antioxidant properties in plant materials (Ahn et al., 2004 and LampartSzczapa et al., 2003).

In general, the present study was undertaken to investigate the effect of gamma irradiation at various doses level on the antioxidant activity properties and total phenolic and flavonoids contents extracted with different solvents of tomato pomace.

Materials:

\section{MATERIALS AND METHODS}

Tomato pomace was obtained from Qaha Egypt For Food DevelopmentCompany,Egypt, Butylatedhydroxytuluen (BHT) 1, 1-Diphenyl-2picrylhydrazyl (DPPH), $\beta$-carotene, gallic acid, quercetin, iron (III) chloride 
and aluminum chloride were purchased from Sigma (St. Louis, MO, USA), Folin- Ciocalteu reagent was purchased from LOBA Chemie, india. All other chemicals used were analytical reagent grade.

\section{Methods:}

\section{Preparation of plant extract:}

Tomato pomace was dried in oven drier at $45 \stackrel{\circ}{\circ} \mathrm{C}$ for $72 \mathrm{hr}$ and grounded. The dried pomace was packed in polyethylene bag each bag was contained $250 \mathrm{~g}$ of dried pomace. Irradiation treatment were carried out at doses of 1,3 and $5 \mathrm{kGy}$ using a ${ }^{60} \mathrm{Co}$ Russian gamma chamber, (dose rate $1.3 \mathrm{kGy} / \mathrm{h}$ ), belonging to Cyclotron Project, Nuclear Research Center, Atomic Energy Authority, Cairo, Egypt.

Dried pomace powder $(10 \mathrm{~g})$ was extracted individually into $100 \mathrm{ml}$ of chloroform: ethyl acetate (1: 1), methanol and acetone: water: glacial acetic acid (70: 29.5: 0.5) separately after soaking in hexane to remove fatty materials (1: 5). All the extracts were subjected to shaking at room temperature overnight at a speed of $200 \mathrm{vib}$. / min. The extracts were filtered through Whatman No. 42 filter paper and the residue was again extracted with $100 \mathrm{ml}$ of respective solvent to ensure the complete extraction of phenolic compounds. Then, the filtrate was subjected to rotary evaporator at $45^{\circ} \mathrm{C}$ under reduced pressure for the removal of solvent. The extracts were stored at $-18^{\circ} \mathrm{C}$ until analyses.

\section{Determination of total phenolic content (TPC):}

Total phenolic content was determined by the Folin-Ciocalteu method according to Arabshahi-Delouee and Urooj (2007).

Determination of total flavonoids content (TFC):

Total flavonoids content was determined by the method according to Ordonet al. (2006).

\section{Antioxidant activity of extracts:}

Because of the differences among the various test systems available, the results of a single method can provide only a limited assessment of the antioxidant properties of a substance (Gianniet al., 2005). For that reason, in this study the antioxidant capacity of each extract was determined through three complementary assay procedures.

\section{DPPH radical-scavenging activity:}

The electron donation ability of the obtained extracts was measured by bleaching of the purple colored solution of DPPH according to the method of Hanatoet al., 1988 and Gülçinet al., 2004. Percentage of antioxidant activity of free radical DPPH was calculated as follow:

$\beta$-Carotene/linoleic acid bleaching ( $\beta C B$ ):

The ability of extracts and synthetic antioxidants to prevent the bleaching of $\beta$-carotene was assessed as described by Keyvanet al. (2007).

Ferric reducing antioxidant power (FRAP):

Oyaizu (1986).

Reducing power of all extracts was measured by the method of 
High performance liquid chromatography (HPLC) analysis:

Fractionation and identification of phenolic compounds in extracts:

Phenolic compounds of unirradiated and irradiated with $3 \mathrm{kGy}$ tomato pomace extracts were estimated in Central Laboratory of Food Tech. Res. Inst., Agric.Res.Center, Giza, Egypt. Phenolic compounds of each sample were identified by comparing their relative retention times with those of the standard mixture chromatogram (Elbadrawy and Sello, 2011). The concentration of an individual compounds was calculated on the basis of peak area measurement, then converted to $\mathrm{mg}$ phenolic / $100 \mathrm{~g}$ dry matter .

Fractionation and identification of flavonoide compounds in acetone extract:

Flavonoide compounds of unirradiated and irradiated with 3 kGy tomato pomace acetone extract were determined by HPLC. The quantification was made with an external standard (Skerget et al., 2005).

Determination of antioxidant activity of acetone extract by the rancimat method:

One $\mathrm{ml}$ of condensed acetone extract of unirradiated and irradiated at 1, 3 and 5 kGy tomato pomace mixed well with sunflower oil using a magnetic stirrer to complete dispersion in the oil. Sunflower oil sample without any addition was kept as a control. The antioxidant activity was determined by the Rancimat method using Rancimat Metrohm 679 as described by Hasenhuttle and Wan (1992) and the induction period (I.P.) was conducted with Rancimat at $100^{\circ} \mathrm{C}$ and calculated at $25^{\circ} \mathrm{C}$ using the temperature coefficient of 2.2 for induction period according to the method reported by Hadron and Zurcher (1974) and 2.5 for expired period. The antioxidant activity and increasing index were calculated using the following equations:

\footnotetext{
Antioxidant activity $=\underline{\text { Induction period of sample }}$ Induction period of control

Increasing index $=$ Induction period of sample -Induction period of control $\times 100$

Induction period of control
}

\section{RESULTS AND DISCUSSION}

\section{Total phenolic compounds (TPC):}

Phenolic compounds are hydroxylated derivatives of benzoic and cinnamic acids and contribute to overall antioxidant activities in the plants. Data inTable(1)indicate that, thesolvent extractionswere affected the concentration of total phenols in irradiated and non-irradiated samples of tomato pomace. The phenolic contents of the control (non-irradiated) samples were found to be $182.58,134.11$ and $78.38 \mathrm{mg} \mathrm{GAE} / 100 \mathrm{~g}^{-1} \mathrm{DW}$ for acetone $70 \%$, methanoland Chloroform: ethyl acetate (1:1) extracts, respectively. It can be inferred from these results that acetone $70 \%$ is the most efficient solvent for extracting phenolic compounds from tomato pomace. This may be attributed to higher polarity and good solubility of acetone (70\%) for phenolic components extraction from plant materials (Wieland et al., 2006). 
Table (1): Total Phenolic and Flavonoide contents of gamma irradiated and non-irradiated tomato pomace extracted by different solvents.

\begin{tabular}{|c|c|c|c|c|c|c|}
\hline \multirow{3}{*}{$\begin{array}{c}\text { Gamma } \\
\text { irradiation } \\
\text { doses (kGy) }\end{array}$} & \multicolumn{6}{|c|}{ Solvents } \\
\hline & \multicolumn{2}{|c|}{$\begin{array}{l}\text { Chloroform: ethyl } \\
\text { acetate }(1: 1)\end{array}$} & \multicolumn{2}{|c|}{ Methanol } & \multicolumn{2}{|c|}{ Acetone $(70 \%)$} \\
\hline & $\begin{array}{c}\text { TPC } \\
78.38\end{array}$ & $\begin{array}{c}\text { TFC } \\
50.16\end{array}$ & $\begin{array}{l}\text { TPC } \\
134.11\end{array}$ & $\begin{array}{l}\text { TFC } \\
62.25\end{array}$ & $\begin{array}{c}\text { TPC } \\
182.58\end{array}$ & $\begin{array}{l}\text { TFC } \\
72.90\end{array}$ \\
\hline 1 & 85.05 & 55.77 & 137.44 & 70.74 & 188.57 & 89.59 \\
\hline 3 & 100.37 & 56.71 & 142.40 & 65.70 & 191.45 & 90.60 \\
\hline 5 & 80.22 & 51.38 & 134.80 & 72.90 & 185.34 & 85.71 \\
\hline
\end{tabular}

Data in the same table show that, the total phenolic contents of irradiated acetone extracts, was $191.45 \mathrm{mg} \mathrm{GAE} / 100 \mathrm{~g}^{-1} \mathrm{DW}$ for a gamma radiation at $3 \mathrm{kGy}$. It seems that 1-5 kGy of irradiation might induce some chemical reactions in components of tomato pomace, which possibly degrade or decompose large molecules into small phenolic molecules, which are readily soluble in acetone and may also be beneficial for the antioxidant properties of tomato pomace. The phenolic and flavonoids contents depend on the cultivar, growing region, climate, maturity, cultivation practice, storage conditions (Poyrazogluet al., 2002) and the methods ofextractions. These compounds are known for their properties to scavenge free radicals and to inhibit lipid oxidation in vitro (Nodaet al., 2002). On the other hand, irradiation treatment at $3 \mathrm{kGy}$ in the same solvent had an increasing in TPC of all extracts particular compared to other treatments at 0,1 and $5 \mathrm{kGy}$.Variyaret al. (1998) found increased the amounts of phenolic acids in irradiated cloves and nutmeg. Harrison and Were (2007) also reported increases in total phenolic content of gamma-irradiated almond skin extract, as compared to the control samples. These increases in phenolic contents were associated with the degradation of tannins (Variyaret al., 1998) and changes in the conformation of the molecules (Topuz and Ozdemir, 2004), as a result of the irradiation treatment. In contrast, Kosekiet al., (2002) reported a decrease in the amount of total phenolic compounds in dehydrated rosemary after irradiation doses of between 10 and $30 \mathrm{kGy}$, with respect to control samples. The difference in the effect of radiation on total phenolic content may be due to plant type, geographical and environmental conditions, state of the sample (solid or dry), phenolic content composition, extraction solvent, extraction procedures, temperature, dose of gamma irradiation.Bhatt et al. (2007) observed that, except for $2.5 \mathrm{kGy}$, the other doses showed a significant dosedependent increase in total phenolics to higher extractability by depolymerization and dissolution of cell wall polysaccharides by irradiation, which was known to increase the activity of phenylalanine ammonialyase, responsible for the synthesis of phenolic compounds. 


\section{Total flavonoids content (TFC):}

Flavonoids, which are the major components of the total phenolic content of tomato pomace, were also quantified in different solvent extracts (Table.1).Data in Table (1) indicate that, theacetone extract of tomato pomace had the highest total flavonoids contents in all extracts of nonirradiated samples. The hightotalcontent of flavonoids $190.60 \mathrm{mg}$ QE $/ 100 \mathrm{~g}^{-1} \mathrm{DW}$ ) was observed with acetone extract of irradiated tomato pomace(3kGy) gamma irradiation, while the lowest level was found in chloroform extract of tomato pomace which exhibited $50.16 \mathrm{mg} \mathrm{QE} /$ $100 \mathrm{~g}^{-1} \mathrm{DW}$. The results confirmed a previous report that flavonoids represent the main group of phenolic compounds in white onion (Yang et al., 2004). In spite of gamma irradiation, it can be observed that 3kGy enhanced TFC compared to 0,1 and $5 \mathrm{kGy}$; this may be due to the same effects of irradiation on TPC mentioned before.

\section{Antioxidant activity of extracts:}

All plant phenolic classes have the structural requirements of free radical scavengers and have potential as food antioxidants (Jayathilankanet al. 2007). The antioxidant activity of phenolic compounds may result from the neutralization of free radicals initiating oxidation processes or from the termination of radical chain reactions. Also the antioxidant activity of phenolic compounds is due to their high tendency to chelate metals. Phenols are very important plant constituents because of their scavenging ability on free radicals due to their hydroxyl groups (Heimet al., 2002). Several studies showed good correlation between the phenols and antioxidant activity. As mentioned by Frankel and Meyer (2000) and Huang et al. (2005) no single method is adequate for evaluating the antioxidant capacity of foods or extracts, since different methods can yield widely diverging results. Thus, several methods based on different mechanisms should be used. Here we applied the DPPH radical-scavenging activity, $\beta$-carotene/linoleic acid bleaching test and the ferric reducing antioxidant power (FRAP) to each extract.

\section{DPPH radical-scavenging activity:}

The effect of antioxidants on DPPH radical-scavenging is thought to be due to their hydrogen-donating ability, $\mathrm{DPPH}^{\circ}$ is a stable free radical and accepts an electron or hydrogen radical to become a stable molecule (Gülçinet al.,2004). The obtained data in Table (2) indicate that,the antioxidant activity with different solvents varied from 35.53 to $69.08 \%$ after 120 min for non-irradiated samples. On the other side, the highest antioxidant activity was observed with acetone extract $(74.05 \%$ after $120 \mathrm{~min})$ of irradiated tomato pomace at 3kGy compared withBHT value $(74.05 \%$ after $120 \mathrm{~min})$. So, the high scavenging ability of acetone extract of irradiated tomato pomace at $3 k G y$ can be correlated to the highest phenolic content. The enhanced antioxidant capacity /activity of a plant after irradiation is mainly attributed either to increased enzyme activity (e.g. phenyl alanine ammonialyase and peroxidase activity) or to the increased extractability from the tissues extractability by depolymerization and dissolution of cell wall polysaccharides by irradiation (Alothman et al., 2009). 
Khalaf H. H. et al.

T2

254 


\section{$\beta$-Carotene/linoleic acid bleaching (BCB):}

Data in Table (3) show that, all extracts were capable of inhibiting the bleaching of $\beta$-carotene by scavenging linoleate-derived free radicals. The order of decreasing efficacy of irradiated and non-irradiated tomato pomace extracts was acetone> methanolic > (chloroform: ethyl acetate). The results reveal that, the scavenging ability of acetone extract $(58.50 \%)$ was the highest one compared with the other extracts of non-irradiated tomato pomace. On the other hand, the irradiation treatment at $3 \mathrm{kGy}$ was enhanced the scavenging ability of all extracts which achieved to $38.42 \%, 53.52 \%$ and $61.14 \%$ for chloroform: ethyl acetate, methanol and acetone extracts, respectively. Data in the same table showed that, the acetone extract of irradiated tomato pomace at $3 \mathrm{kGy}$ was the highest extract in $\beta$-carotene/ linoleic acid bleaching ( $\beta C B)$ system compared to other extracts and synthetic antioxidants (BHT).Kumariet al. (2009) also showed similar results with triphala, wherein they have found out an increase in gallic acid concentration and total phenolics in the water extract due to irradiation that leads to increase in antioxidant property. On the other hand the decrease in antioxidants caused in extracts of irradiated tomato pomace at 5 kGy compared to $3 \mathrm{kGy}$ could be attributed in general, to the formation of radiation-induced degradation products or the formation of free radicals (Sajilata and Singhal, 2006). Breitfellneret al. (2002) have reported that $Y$ irradiation (1-10 kGy) of strawberries lead to the degradation of phenolic acids like cinnamic, p-coumaric, gallic, and hydroxybenzoic acids. The hydroxylation (decomposition) of these phenolic acids has been attributed to the formation of free hydroxyl $\left(\mathrm{OH}^{-}\right)$radicals during the treatment.

\section{Ferric reducing antioxidant power (FRAP):}

An irradiation dose-dependent increase in the ferric reducing power value was observed in the tomato pomace extracts (Table, 3). An increasing in the ferric reducing power was observed in 1 and $3 \mathrm{kGy}$ compared to with 0 and $5 \mathrm{kGy}$ doses in all extracts. However, the results revealed that the ferric reducing power value of acetone extract (1.745) was the highest one compared with the other investigated extracts of non-irradiated tomato pomace. On the other hand, the irradiation treatment at $3 \mathrm{kGy}$ was enhanced ferric reducing power value of all extracts which achieved to $1.580,1.780$ and 1.900 for Chloroform: ethyl acetate, Methanol and Acetone extracts, respectively. From these results, overall, the acetone extract of irradiated tomato pomace at $3 \mathrm{kGy}$ was the highest extract in ferric reducing power value compared to the other extracts and synthetic antioxidants (BHT). Total phenolic content and ferric reducing power are related with each other. $\mathrm{Fe}$ (III) reduction is often used as an indicator of electron-donating activity, which is an important mechanism of phenolic antioxidant action (Dorman et al., 2003). The FRAP (ferrous reducing antioxidant power) assay is commonly used for assessing antioxidant activity, since it has high sensitivity, and is rapid and inexpensive. In the present investigation, there was a significant and/or negligible increase in the FRAP of all irradiated tomato pomace when compared to non-irradiated tomato pomace extracts. 
Khalaf H. H. et al.

Table (3): $\beta$-carotene/ linoleic acid bleaching ( $\beta C B$ ) system and absorbance of ferric reducing power (FRAP) of gamma irradiated and non-irradiated tomato pomace extracted by different solvents compared with BHT.

\begin{tabular}{|c|c|c|c|c|c|c|}
\hline \multirow{3}{*}{$\begin{array}{l}\text { Gamma } \\
\text { irradiation } \\
\text { doses } \\
\text { (kGy) }\end{array}$} & \multicolumn{6}{|c|}{ Solvents } \\
\hline & \multicolumn{2}{|c|}{$\begin{array}{c}\text { Chloroform : ethyl } \\
\text { acetate }(1: 1)\end{array}$} & \multicolumn{2}{|c|}{ Methanol } & \multicolumn{2}{|c|}{ Acetone $(70 \%)$} \\
\hline & $\begin{array}{c}\text { B- } \\
\text { carotene }\end{array}$ & FRAP & $\begin{array}{c}\text { B- } \\
\text { carotene }\end{array}$ & FRAP & $\begin{array}{c}\text { B- } \\
\text { carotene }\end{array}$ & FRAP \\
\hline 0 & 35.04 & 1.373 & 50.44 & 1.632 & 58.50 & 1.745 \\
\hline 1 & 37.98 & 1.516 & 52.2 & 1.668 & 59.24 & 1.863 \\
\hline 3 & 38.42 & 1.580 & 53.52 & 1.780 & 61.14 & 1.900 \\
\hline 5 & 36.51 & 1.420 & 51.76 & 1.889 & 58.80 & 1.815 \\
\hline $\begin{array}{c}\text { BHT } \\
\text { (200ppm) }\end{array}$ & 60.85 & 1.019 & 60.85 & 1.019 & 60.85 & 1.019 \\
\hline
\end{tabular}

Fractionation and identification of phenolic compounds in extracts:

The non-irradiated and gamma irradiated tomato pomace with $3 \mathrm{kGy}$ doses and extracted by different solvents were subjected to HPLC. Data in Table (4) show the separation a large number of compounds of which twelve phenolic acids were identified. The phenolic acids were identified according to their retention time in comparison with authentic samples. The irradiation treatment with $3 \mathrm{kGy}$ of tomato pomace led to phenolics content increasing. For example, the cholorogenic acid, this corresponding concentration was $2.661,2.625$ and $1.680 \mathrm{mg} / 100 \mathrm{~g}$ of non-irradiated tomato pomace in chloroform: ethyl acetate, methanol and acetone extracts, respectively. While, the concentration of cholorogenic acid was increased to 9.395, 12.301 and $2.411 \mathrm{mg} / 100 \mathrm{~g}$ in gamma irradiated (3kGy) tomato pomace of the same extracts, respectively. Phenols are very important plant constituents because of their scavenging ability on free radicals due to their hydroxyl groups (Heim et al., 2002). Several studies showed good correlation between the phenols and antioxidant activity (Haung et al., 2005 and Silva et al., 2006).

Table 4. Identified phenolic compounds $(\mathrm{mg} / 100 \mathrm{gm})$ of non-irradiated and gamma irradiated tomato pomace with $3 \mathrm{kGy}$ extracted by different solvents.

\begin{tabular}{ccccccc}
\hline & \multicolumn{3}{c}{ Phenolic compounds (mg /100gm) } \\
\cline { 2 - 7 } $\begin{array}{c}\text { Phenolic } \\
\text { compounds }\end{array}$ & $\begin{array}{c}\text { Chloroform : ethyl acetate } \\
(\mathbf{1 : 1 )}\end{array}$ & \multicolumn{2}{c}{ Methanol } & $\begin{array}{c}\text { Acetone :water : } \\
\text { glacial acetic acid } \\
\text { (70:29.5:0.5) }\end{array}$ \\
\cline { 2 - 7 } & $\mathbf{0 ~ k G y}$ & $\mathbf{3 ~ k G y}$ & $\mathbf{0 ~ k G y}$ & $\mathbf{3 ~ k G y}$ & $\mathbf{0 ~ k G y}$ & $\mathbf{3 ~ k G y}$ \\
\hline Protocatechuic & 7.277 & 5.088 & 7.609 & 16.402 & 3.953 & 3.543 \\
Catechein & 1.645 & 1.397 & 1.201 & 1.394 & 5.566 & - \\
Catechol & 0.973 & 5.996 & 1.148 & 5.102 & 3.037 & - \\
Chlorogenic & 2.661 & 9.395 & 2.625 & 12.301 & 1.680 & 2.411 \\
Caffeic & 7.795 & 5.171 & 1.105 & 0.909 & 0.448 & 2.383 \\
Vanillic & 2.726 & 2.162 & 0.684 & 25.532 & 2.745 & 0.454 \\
Caffeine & 0.589 & 3.190 & 0.529 & 1.431 & 0.894 & 2.705 \\
Ferulic & 4.252 & 0.891 & 3.645 & 1.895 & 36.078 & 2.192 \\
Salicylic & 5.933 & 5.164 & 17.024 & 13.38 & 1.774 & 18.364 \\
Ellagic & 2.242 & 6.731 & 4.084 & 2.958 & 2.118 & 9.947 \\
Coumarin & 1.633 & 0.846 & 0.612 & 1.009 & - & - \\
Cinnamic & 1.505 & 1.616 & 0.819 & 1.020 & - & 1.988 \\
\hline
\end{tabular}




\section{Fractionation and identification of flavonoid compounds in acetone extract:}

The non-irradiated and gamma irradiated tomato pomace with 3 kGyand extracted by the acetone $(70 \%)$ solvent was subjected to HPLC. Data in Table (5)show the separation of eight flavonoids compounds were identified. TheFlavonoid compounds were identified according to theirretention time in comparison with authentic samples.It wasclear that Rutin was the abundant flavonoid compound followed by Rosmarinic, Luteolin, Quercitrin, Hespertin,NarengininandQuerctin,whereasKampferolwas the least one. The irradiation treatment with $3 \mathrm{kGy}$ of tomato pomace led to flavonoids content increasing. For example, the concentration of Rutinincreased from 9.55 to $11.43 \mathrm{mg} / 100 \mathrm{gof}$ non-irradiated and gamma irradiated tomato pomace ( $3 \mathrm{kGy}$ ) acetone extract, respectively. In the same idea, Gonzalezet al.(2011) found that tomato peel contains several flavonoids withbeneficial effects for human health such as rutin, naringeninand quercetin. Rutin has been associated with markedly decreasedhepatic and cardiac levels of triglycerides (Fernandez et al.,2010), and it has been suggested that it has anti-inflammatoryproperties (Guardia et al., 2001). Naringenin has beensuggested as an antioxidant, an anti-inflammatory, and a regulatorof fat metabolism and sex hormone metabolism. Finally,quercetin has been reported to exhibit antioxidative, anticarcinogenic, anti-inflammatory, anti-aggregation, andvasodilating effects (Erlund, 2004).

Table5. Identified flavonoide compounds $(\mathrm{mg} / 100 \mathrm{~g})$ of non-irradiated and gamma irradiated tomato pomace at $3 \mathrm{kGy}$ of acetone extract.

\begin{tabular}{ccc}
\hline \multirow{2}{*}{ Flavonoide } & \multicolumn{2}{c}{ Flavonoids compounds (mg /100g) } \\
\cline { 2 - 3 } compounds & \multicolumn{2}{c}{ Acetone (70\%) } \\
\cline { 2 - 3 } & OkGy & 3kGy \\
\hline Rosmarinic & 5.02 & 5.93 \\
Rutin & 9.55 & 11.43 \\
Quercitrin & 2.76 & 3.30 \\
Narenginin & 2.25 & 1.50 \\
Querctin & 1.34 & 1.40 \\
Hespertin & 2.28 & 2.42 \\
Kampferol & 1.04 & - \\
Luteolin & 3.38 & - \\
\hline
\end{tabular}

Effect of gamma irradiated and non-irradiated tomato pomace acetone extracts on oxidative stability of sunflower oil.

Lipid oxidation is one of the major deteriorative reactions especially, in highly processed foods such as margarines, butters and other fats. Accordingly, it is important to predict the oxidative stability of given food byrapid and reliable methods in order to determine shelf life and evaluate the effectof protective antioxidants (Thomsenet al.,2000). The induction period is determined at the time whichthe conductivity exponentially increases. The induction period has been definedas the length of time until progressive 
oxidation exponentially accelerates thegeneration of oil degradation compounds (Kristott, 2000). Therefore, forcedoxidative conditions were used to determine the effect of addition of acetone extracts of gamma irradiated and non-irradiated tomato pomace on shelf life or oxidative stability of sunflower oil.

Data in Table (6) notice that, the induction period at $100^{\circ} \mathrm{C}$ of sunflower oil was increased to $10.5 \mathrm{hr}$. as a result of addition BHT (200 ppm) compared with that of control sample (8.38hr.). Also, it is clear that, the oxidative stability (10.6 hr.) was obtained using addition of acetone extract of gamma irradiated tomato pomace at $3 \mathrm{kGy}$ which increased the shelf life from 12.43 to 15.73 month. From the aforementioned data, it could be concluded that, the addition of acetone extract of gamma irradiated tomato pomace at 3 kGy improved the antioxidant activity and increasing index (1.26 and 26.49 $\%$, respectively). As well as, it can be used as a new source of natural antioxidants to improve the oxidative stability of sunflower oil. These results are in accordance with those obtained byHemeda (1994).

Table (6): Effect of gamma irradiated and non-irradiated tomato pomace acetone extracton oxidative stability of sunflower oil.

\begin{tabular}{lcccc}
\hline \multirow{2}{*}{$\begin{array}{l}\text { Gamma } \\
\text { irradiation doses } \\
\text { (kGy) }\end{array}$} & $\begin{array}{c}\text { Induction } \\
\text { periodat } \\
\left(100^{\circ} \mathrm{C}\right)\end{array}$ & $\begin{array}{c}\text { Shelf life at } \\
25^{\circ} \mathrm{C} \text { (month) }\end{array}$ & $\begin{array}{c}\text { Antioxidant } \\
\text { activity }\end{array}$ & $\begin{array}{c}\text { Oncreasing index } \\
(\%)\end{array}$ \\
\hline Control & 8.38 & 12.43 & 0 & 0 \\
(0kGy) & 10 & 14.83 & 1.19 & 19.33 \\
$(1 \mathrm{kGy})$ & 10.4 & 15.43 & 1.24 & 24.11 \\
(3kGy) & 10.6 & 15.73 & 1.26 & 26.49 \\
(5kGy) & 10.2 & 15.13 & 1.21 & 21.71 \\
BHT (200ppm) & 10.5 & 15.58 & 1.25 & 25.30 \\
\hline
\end{tabular}

\section{CONCLUSION}

Generally, this study concluded that gamma radiation dose up to 3 kGy can improve the antioxidant activity of tomato pomace extracts, in addition to the enhancement of scavenging activity and increase in the phenolic and flavonoid contents. This study therefore, supports the use of gamma radiation as a phytosanitary treatment for tomato pomace and calls for further investigations to elucidate its effect on the other biological activities and constituents of the plant.

\section{REFERENCES}

Ahn, H. J.; Kim, J. H.; Jo, C.; Kim, M. J. and Byun, M. W. (2004). Comparison of irradiated phytic acid and other antioxidants for antioxidant activity. Food Chemistry, 88: 173-178.

Alothman, M.; Bhat, R. and Karim A. A. (2009). Effects of radiation processing on phytochemicals and antioxidants in plant produce. Trends In Food Science and Technology, 20 (2): 201-212. 
Al-Wandawi, H.; Abdul Rehman, M. H. and Al Shaikhly, K.A. (1985).Tomato processing wastes as essential raw materials source. Journal of Agriculture and Food Chemistry, 33: 804-807.

Arabshahi-Delouee, S. and Urooj, A. (2007). Antioxidant properties of various solvent extracts of mulberry (Morus indica L.) leaves. Food Chemistry, 102 (4): 1233-1240.

Aravantinos-Zafiris, G., and Oreopoulou, V. (1992). The effect of nitric acid extraction variables on orange pectin. Journal Science Food Agriculture, $60: 127$.

Bhat, R.; K. R. Sridhar and K. Tomita-Yokotani (2007). Effect of ionizing radiation on antinutritional features of velvet bean seeds (mucuna pruriens). Food Chemistry, 103(3): 860-866.

Breitfellner, F.; Solar, S. and Sontag, G. (2002). Effect of Y-irradiation on phenolic acids in strawberries. Journal Food Science, 67: 517-521.

Byun, M. W.; Son, J. H.; Yook, H. S.; Jo, C. and Kim, D. H. (2002). Effect of gamma irradiation on the physiological activity of Korean soybean fermented foods, Chungkookjang and Doenjang. Radiation Physics and Chemistry, 64: 245-248.

Byun, M. W.; Yook, H. S.; Kim, K. S. and Chung, C. K. (1999). Effects of gamma irradiation on physiological effectiveness of Korean medicinal herbs. Radiation Physics Chemistry, 54: 291-300.

Cantos, E. ; Garcia-Viguera, C. ; Pascal-Teresa, S. D. and Tomas-Barberan, F. (2000). Effect of postharvest ultraviolet irradiation on resveratrol and other phenolics of cv. Napolean table grapes. Journal of Agricultural and Food Chemistry, 48, 4606-4612.

Dorman H. J. D.; Kosar, M.; Kahlos, K.; Holm, Y. And Hiltunen, R.(2003). Antioxidant properties and composition of aqueous extracts from Mentha species, hybrids, varieties, and cultivars. J. Agric. Food Chemistry, 51:4563-4569.

Elbadrawy, E. and Sello, A. (2011). Evaluation of nutritional value and antioxidant activity of tomato peel extracts. Arabian Journal of Chemistry, In Press, Corrected Proof, Available online, www.sciencedirect.com.

Erlund, I. (2004). Review of the flavonoids quercetin, hesperetin, and naringenin. Dietary sources, bioactivities, bioavailability, and epidemiology. Nutrition Research, 24, 851-874.

FAOSTAT. (2012). FAOSTAT agriculture production database. http://faostat.fao.org/site/339/default.aspx.

Fernandez, A. A. H.; Novelli, E. L. B.; Okoshi, K.; Okoshi, M. P.; Di Muzio, B. P. and Guimaraes, J. F. C. (2010). Influence of rutin treatment on biochemical alterations in experimental diabetes. Biomedicine and Pharmacotherapy, 64: 214-219

Food and Drug Administration (1981). Irradiation in the production, processing, and handling of food; final rule. 21 CFR Part 179. Federal Register, 51: 13376-13399. 
Frankel, E. and Meyer, A. S. (2000). The problems of using one-dimensional methods to evaluate multifunctional food and biological antioxidants. Journal Science Food Agriculture, 80:1925-1941

George, B.; Kaur, C.; Khurdiya, D. S. and Kapper, H. C. (2004). Antioxidants in tomato (Lycopersicon esculentum) as a function of genotype. Food Chemistry, 84: 45-51.

Gianni, S.; Silvia, M.; Mariavittoria, M.; Martina, S.; Stefano, M. and Matteo, R. (2005). Comparative evaluation of 11 essential oils of different origin as functional antioxidants, antiradicals and antimicrobials in foods. Food Chemistry, 91:621-632

Giovanelli, G. and Paradise, A. (2002). Stability of dried and intermediate moisture tomato pulp during storage. Journal of Agriculture and Food Chemistry, 50, 7277-7281.

Gonzalez, I. N.; Valverde, V. G.; Alonso, J. G. and Periago, M. G. (2011). Chemical profile, functional and antioxidant properties of tomato peel fiber. Food Research International, 44: 1528-1535.

Guardia, T.; Rotelli, A. E.; Juarez, A. O. and Pelzer, L.E. (2001). Antiinflammatory properties of plant flavonoids. Effects of rutin, quercetin and hesperidin on adjuvant arthritis in rat. IL Farmaco, 56: 683-687.

Gülçin, İ.; Bursal, E.; Şehitoğlu, H. M.; Bilsel, M. and Gören, A. C. (2010). Polyphenol contents and antioxidant activity of lyophilized aqueous extract of propolis from Erzurum, Turkey. Food and Chemical Toxicology, 48(8-9) :2227-2238.

Gülçin, I.; Kufrevioglu, O. I.; Oktay, M. and Buyukokuroglu, M.E. (2004). Antioxidant, antimicrobial, antiulcer and analgesic activities of nettle (Urtica dioica L.). Journal Ethnopharmacology, 90: 205-215

Hadorn, H. and Zurcher, L. ( 1974 ). Automated AOM test for fat stability. Journal of the American Oil Chemists' Society, 61(3):534-536.

Hanato, T.; Kagawa, H.; Yasuhara, T. and Okuda, T. (1988). Two new flavonoids and other constituents in licorice root: their relative astringency and radical scavenging effects. Chemical and Pharmaceutical Bulletin, 36: 2090-2097.

Harrison, K. and Were, L. M. (2007). Effect of gamma irradiation on total phenolic content yield and antioxidant capacity of Almond skin extracts. Food Chemistry, 102: 932-937.

Hasenhuttle, B. L. and Wan, P. J. (1992). Temperature effects on the determination of oxidative stability with the Metrohm Rancimat. Journal of the American Oil Chemists' Society, 69 (6): 525-527.

Haung, D.; Ou, B. and Prior, R. L. (2005). The chemistry behind antioxidant capacity assays. Journal of Agriculture and Food Chemistry, 53: 18411856.

Heim, K. E.; Taigliaferro, A. R. and Bobilya, D. J. (2002). Flavonoid antioxidants: chemistry, metabolism and structure-activity relationships. The Journal of Nutritional Biochemistry, 13: 572-584

Hemeda, H.M. (1994). Isolation of natural antioxidants from vegetables waste by products. Journal. Agriculture Science, Mansoura University, 19 (9): 2953-2960. 
Huang, D.; Band, O. and Prior, R. L. (2005). The chemistry behind antioxidant capacity assays. Journal of Agriculture and Food Chemistry, 53:1841-1856.

Jayathilankan, K.; Sharma, G. K.; Radhakrishna K. and Bawa A. S. (2007). Antioxidant potential of synthetic and natural antioxidants and its effect on warmed-over-flavour in different species of meat. Food Chemistry, 105: 908-916.

Jo, C.; Son, J. H.; Shin, M. G. and Byun, M. W. (2003). Irradiation effects on color and functional properties of persimmon (Diospyros kaki L. folium) leaf extract and licorice (Glycyrrhiza uralensis Fischer) root extract during storage. Radiation Physics and Chemistry, 67: 143-148.

Kandaswami, C. and Middleton, E. (1997). Flavonoids as antioxidants, in: Natural Antioxidants, Chemistry, Health Effects and Practical Applications, F. Shahidi, ed., AOCS Press, Champaign Illinois, pp. 174194.

Keyvan, D. H. J.; Damien, D.; Into, L. and Raimo, H. (2007).Chemical composition and antioxidative activity of Moldavian balm (Dracocephalum moldavica L.) extracts. LWT - Food Science Technology, 40:1655-1663

Kim, J. K.; Jo, C.; Hwang, H. J.; Park, H. J.; Kim, Y. J. and Byun, M. W. (2006). Color improvement by irradiation of Curcuma aromatica extract for industrial application. Radiation Physics Chemistry, 75, 449-452.

King, A. J. and Zeidler, G. (2004). Tomato pomace may be a good source of vitamin $E$ in broiler diets. Californiea Agriculture, 58, 59-62.

Kiokias, S. and Gordon, M. H. (2004). Antioxidant properties of carotenoids in vivo and in vitro. Food Reviews International, 20:99.

Koseki, P. M.; Villavicencio, A. L. C. H.; Britoa, M. S.; Nahme, L. C.; Sebastiao, K. I. and Rela, P. R. (2002). Effects of irradiation in medicinal and eatable herbs. Radiation Physics and Chemistry, 63, 681-684.

Kristott, J. (2000). The Stability and Shelf-life of Food, ch. 12 (eds. D. Kilcast, P. Subramaniam). CRC Woodhead Publishing Limited, Cambridge, pp. 279-311.

Kumari, N.; Kumar, P.; Mitra, D.; Prasad, B.; Tiwary, B. N. and Varshney, L. (2009). Effects of ionizing radiation on microbial decontamination, phenolic contents, and antioxidant properties of triphala. Journal Food Science, 74 (3): M109-M1113.

Lampart-Szczapa, E.; Korczak, J.; Nogala-Kalucka, M. and ZawirskaWojtasiak, R. (2003). Antioxidant properties of lupin seed products. Food Chemistry, 83, 279-285.

Lario, Y. ; Sendra, E. ; Garcı'a-Perez, J. ; Fuentes, C. ; Sayas-Barbera, E. and Fernandez-Lopez, J. (2004). Preparation of high dietary fiber powder from lemon juice by products. Innovative Food Science and Emerging Technologies, 5 (1): 113-117.

Lee, S. C.; Jeong, S. M.; Kim, S. Y.; Nam, K. C. and Ahn, D. U. (2005). Effect of far-infrared irradiation on the antioxidant activity of defatted sesame meal extracts. Journal of Agricultural and Food Chemistry, 53 (5), 14951498. 
Lee, S.; Kim, J.; Jeong, S.; Kim, D.; Ha, J. and Nam, K. (2003). Effect of farinfrared radiation on the antioxidant activity of rice hulls. Journal of Agricultural and Food Chemistry, 51, 4400-4403.

Liadakis, G. (1999). Utilization of By-Products of Tomato Industrial Processing, Ph.D thesis, National Technical University of Athens, Athens, Greece.

Martinez-Valvercle, I. ; Periage, M. J. ; Provan, G. and Chesson, A. (2002). Phenolic compounds, lycopene and antioxidant activities in commercial varieties of tomato (lycopersicon esculentum). Journal of the Science of Food and Agriculture, 82: 323-330.

Noda, Y.; Kaneyuka, T.; Moriand, A. and Packer L. (2002). Antioxidant activities of pomegranate fruit extract and its anthocyanidins: delphinidin, cyanidin, and pelargonidin. Journal of Agricultural and Food Chemistry, 50: $166-171$.

Ordon, JD.; Gomez, MA. and Vattuone, MI. (2006). Antioxidant activities of Sechium edule (Jacq.) Swartz extracts. Food Chemistry, 97:452-458

Oyaizu, M. (1986). Studies on product of browning reaction prepared from glucose amine. Japanese Journal Nutritional,44: 307-315.

Poyrazoglu, E.; Gökmen, V. and N.Artık (2002). Organic acids and phenolic compounds in pomegranates (Punica granatum L.) grown in Turkey. Journal of Food Composition and Analysis, 15: 567-575.

Sahu, S. C. and Green, S. (1997). Food antioxidants: Their dual role in carcinogennesis, in: Oxidants, Antioxidants and Free Radicals, S. Baskin and H. Salem, eds., Taylor and Francis, Washington, pp. 329330

Sharma, S. K. and Le Maguer, M. (1996). Lycopene in tomatoes and tomato pulp fractions. Italian Journal of Food Science, 2: 107-113.

Silva, E. M.; Souza, J. N. S.; Rogez, H.; Rees, J. F. and Larondella, Y. (2006). Antioxidant activities and polyphenolic contents of fifteen selected plant species from the Amazonian region. Food Chemistry, 101 (3): 1012-1018.

Skerget, M.; Kotnik, P.; Hadolin, M.; Hras, A. R.; Simonic, M. and Knez, Z. (2005). Phenols, proanthocyanidins, flavones and flavonols in some plant materials and their antioxidant activities. Food Chemistry, 89: 191198.

Stewart, A. J.; Bozonnet, S.; Mulluen, W.; Jenkis, G. I.; Lean, M. E. J. and Crozier, A. (2000). Occurrence of flavonols in tomato and tomato based products. Journal of Agriculture and Food Chemistry, 48, 2663-2669.

Thomsen, M. K.; Kristensen, D. and Skibsted, L. H. (2000 ). Electron spin resonance spectroscopy for determination of the oxidative stability of food lipids. Journal of the American Oil Chemists' Society, 77:725-730.

Topuz, A. and Ozdemir, F. (2004). Influences of gamma irradiation and storage on the capsaicinoids of sun-dried and dehydrated paprika. Food Chemistry, 86: 509-515.

Variyar, P.; Bandyopadhyay, C. and Thomas, P. (1998). Effect of gamma irradiation on the phenolic acids of some Indian spices. International Journal of Food Science and Technology, 33: 533-537. 
Wieland, P.; Ferran, S.; Wilfried, D.; Andreas, P.; Irene, G., and Diego J. (2006). An industrial approach in the search of natural antioxidants from vegetable and fruit wastes. Food Chemistry, 97:137-150.

Yang, J.; Meyers K. J.; Van der Heide, J. and Liu, R. H. (2004). Varietal differences in phenolic content and antioxidant and antiproliferative activities of onions. Journal of Agriculture and Food Chemistry, 52:67876793.

الخواص المضادة للأكسدة لبعض مستخلصات تفل الطماطم المعامل بأثعة جامـا

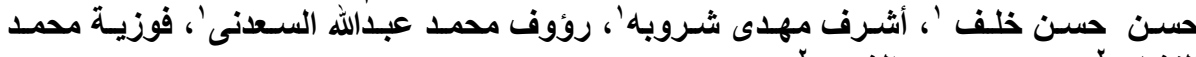

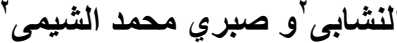

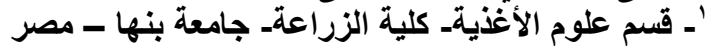

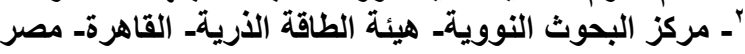

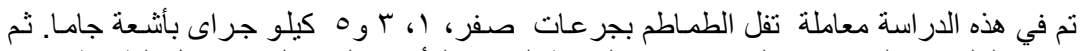

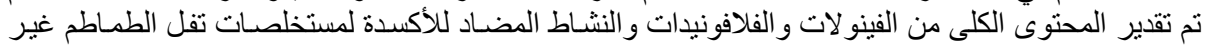

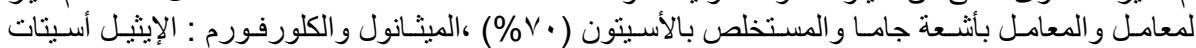

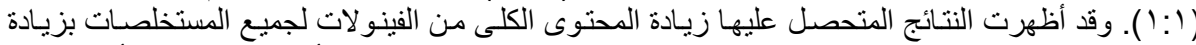

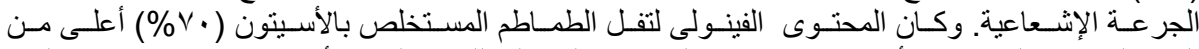

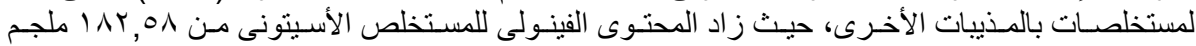

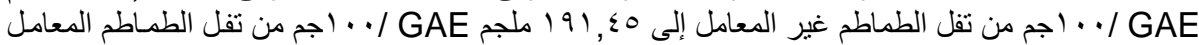

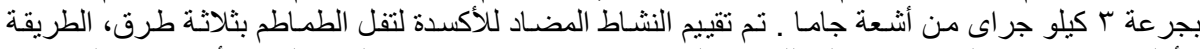

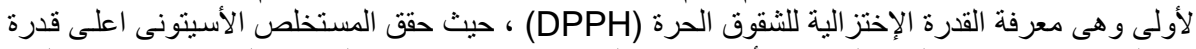

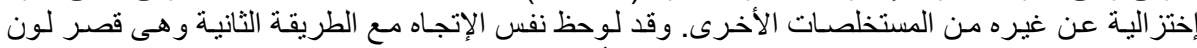

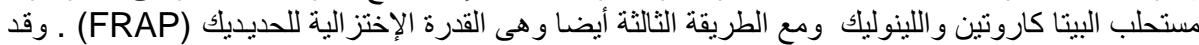

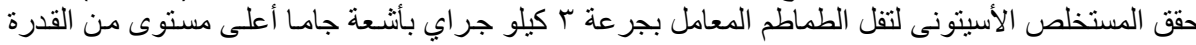

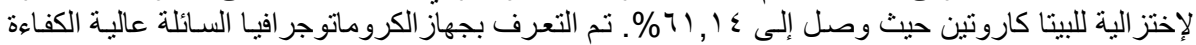

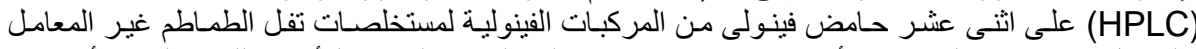

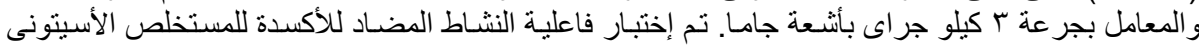

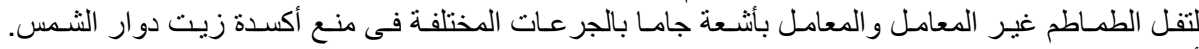

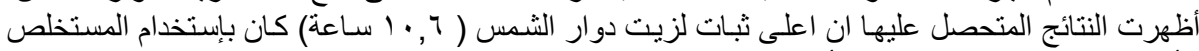

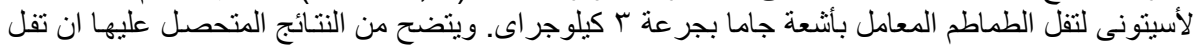

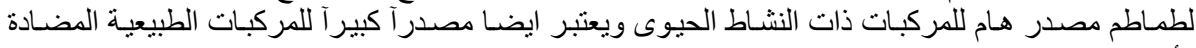

كلية الزراعة - جامعة المنصورة

كلية الزراعة - جامعة بنها

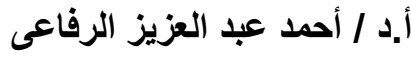

أ.د / همام الطوخى محمد بهلول 

Table (2): DPPH radical scavenging activity of gamma irradiated and non-irradiated tomato pomace extracted by different solvents compared with BHT.

\begin{tabular}{|c|c|c|c|c|c|c|c|c|c|c|c|c|}
\hline \multirow{4}{*}{$\begin{array}{c}\text { Gamma } \\
\text { irradiation } \\
\text { doses (kGy) }\end{array}$} & \multicolumn{12}{|c|}{ Induction periods ( $\mathrm{min}$ ) } \\
\hline & & & & & \multirow{2}{*}{\multicolumn{4}{|c|}{$\begin{array}{l}\text { Solvents } \\
\text { Methanol }\end{array}$}} & & & & \\
\hline & \multicolumn{4}{|c|}{ Chloroform : ethyl acetate (1:1) } & & & & & \multicolumn{4}{|c|}{ Acetone (70\%) } \\
\hline & 0 & 30 & 60 & 120 & 0 & 30 & 60 & 120 & 0 & 30 & 60 & 120 \\
\hline 0 & 21.78 & 30.18 & 32.06 & 35.53 & 41.89 & 53.74 & 56.07 & 59.31 & 35.06 & 62.35 & 66.64 & 69.08 \\
\hline 1 & 22.17 & 30.94 & 32.9 & 36.26 & 43.46 & 54.78 & 57.66 & 61.12 & 37.5 & 63.39 & 69.81 & 72.78 \\
\hline 3 & 22.66 & 33.49 & 35.42 & 38.07 & 44.63 & 55.53 & 58.5 & 62.12 & 37.99 & 64.33 & 70.37 & 74.05 \\
\hline 5 & 22.07 & 30.75 & 32.71 & 35.99 & 42.38 & 54.12 & 56.45 & 59.76 & 35.45 & 63.1 & 67.38 & 69.98 \\
\hline $\begin{array}{c}\text { BHT } \\
\text { (200ppm) }\end{array}$ & 23.69 & 47.11 & 61.13 & 68.81 & 23.69 & 47.11 & 61.13 & 68.81 & 23.69 & 47.11 & 61.13 & 68.81 \\
\hline
\end{tabular}


Khalaf H. H. et al.

Khalaf H. H. et al.

Khalaf H. H. et al.

Khalaf $H$. H. et al.

Khalaf H. H. et al.

Khalaf H. H. et al.

Khalaf $H$. H. et al.

Khalaf H. H. et al.

Khalaf $H$. H. et al.

Khalaf H. H. et al.

Khalaf $H$. H. et al.

Khalaf $H$. H. et al.

Khalaf H. H. et al.

Khalaf $H . H$. et al

Khalaf H. H. et al.

Khalaf H. H. et al.

Khalaf $H$. $H$ et al.

Khalaf $H$. H. et al.

Khalaf $H$. H. et al.

Khalaf $H . H$ et al.

Khalaf H. H. et al.

Khalaf H. H. et al. 